\title{
Identity construction: A comparison between Turkish Muslims in Australia and Germany
}

\author{
Tuba Boz ${ }^{*}$ \\ Gary Bouma*
}

\begin{abstract}
The essentialization of identity coupled with its confused association with loyalty has ensured that issues related to identity are at the forefront of politics, and are used as a platform to generate moral panics which are fuelled by the mass corporate media. Different sociopolitical contexts affect identity construction among Turkish Muslims in Germany and Australia. Based on qualitative interview data collected in 2008 and 2009 in Germany and Australia, this paper examines the circumstances that influence the self-conception of the Turkish Muslims in both countries.

The different political and demographic circumstances of each country are described and their impact on identity formation taken into account. Then we use labeling theory, that is, differences in the language, concepts and official descriptions used by the powerful in each society to label minority groups (Akers 1999), in order to examine the impact of top-down government policies on identity construction among Turkish communities in Australia and Germany a major example of this being the contrast between Australia's multicultural policies with Germany's assimilationist integration policies.
\end{abstract}

Keywords: Identity, labeling, Muslim, Turkish, Australia and Germany, Multiculturalism

\footnotetext{
Corresponding author: Tuba Boz, Faculty of Arts and Social Scinces, International Sarajevo University, Bosnia Herzegovina, e-mail: boz.tuba@gmail.com

* Corresponding author: Gary Bouma, School of Political and Social Inquiry, Monash University, Australia, e-mail: Gary.Bouma@monash.edu
} 


\section{Identity construction: A comparison between Turkish Muslims in Australia and Germany}

The essentialization of identity coupled with its confused association with loyalty has ensured that issues related to identity are at the forefront of politics, and are used as a platform to generate moral panics which are fuelled by the mass corporate media. Globalization, the movements of people, cultures and capital through the impact of global events and mass communication technologies (Appadurai 1996), have contributed to the politicization of identity raising concerns of loyalty in many parts of the world.

Different socio-political contexts affect identity construction among Turkish Muslims in Germany and Australia. Based on qualitative interview data collected in 2008 and 2009 in Germany and Australia, this paper explores the circumstances that influence the self-conception of the Turkish Muslims in both countries. Interviews were conducted with a range of Turkish and Turkish Islamic organizations including mosques, education centers, cultural organizations, businesses, professional associations, academics, politicians, welfare and women's organizations among others, in both countries.

The different political and demographic circumstances of each country are first described and their impact on identity formation taken into account. Then we use labeling theory, that is, differences in the language, concepts and official descriptions used by the powerful in each society to label minority groups (Akers 1999), in order to explore the impact of top-down government policies on identity construction among Turkish communities in Australia and Germany - a major example of this being the contrast between Australia's multicultural policies with Germany's assimilationist integration policies.

Moreover, we do not limit our discussion to the 'official' labels or policies of government. The politicization of debates concerning migrant integration, identity and loyalty are also framed by those with the means and access to voice who influence public opinion and government policy. Labeling groups as deviant or presenting them as unwilling to integrate and contribute to society has an impact on the socio-political environment in which identity is developed and has an impact on the perceptions of the wider-society.

The complexities of using such definitions as 'Muslim', 'Turkish', 'immigrant', 'minority', 'Australian', 'German' - and in particular the classification 'Turkish' - must be clarified from the outset 
In this paper, the term 'Turkish' includes both Turkish immigrants as well as those born in Australia with Turkish ancestry. Similarly, for the purpose of this paper, a distinction is not made between Turkish immigrants to Germany and those who were born in Germany, having Turkish ancestry. Moreover, we do not exclude in our definition those Turkish immigrants and second generation Turks who have forgone their Turkish citizenship in order to become German citizens.

\section{Turkish Muslims in Australia and Germany - socio-political differences}

Our interviews and observations revealed that the Turkish communities in Germany and Australia are notably similar in their day-to-day lives, values, cultures and family relations. Both communities were primarily concerned with providing for and educating their families, maintaining a satisfactory level of employment and securing health care when needed the primary concern of most families around the world. The differences between these two groups are most apparent in the relationship between the State and the community in the respective country and demographic differences. The different socio-political circumstances that influence the identity construction of Turkish Muslims in Germany and Australia can be traced back to the early days of migration, the 1960s and 1970s, when there was demand for foreign labor to supply and promote the economic development of Germany and Australia. This demand for people led to the signing of bilateral migration agreements between Turkey and these two countries.

There was an appreciable social policy difference between the 'welcome' given in each of these countries. This can be summed up in the difference between the official category of immigration offered: Germany offered gastarbeiter (guest worker) status while Australia offered 'Permanent Resident' status. We propose that the very labels 'guest-worker' (Gastarbeiter) and 'permanent migrant' play a significant role in influencing identities of Turkish Muslims in the respective countries. Although the term guest-worker may no longer have relevance, its initial use has framed the context of identity construction of Turkish immigrants in Germany. While the guest-worker may be welcome as a 'guest' for a period of time, the 'permanent migrant' has immigrated to a new home, and is welcome - permanently.

Guest workers were expected to be temporary, to return after a period of time and not to become citizens and take a civic role in the 
society. Permanent Residents were seen as coming to stay, to put down roots, to become part of the society, and to take up citizenship which was available after two years of residence. This difference in social policy is critical to the way the migrants saw themselves. In one case, migrants were allowed and invited to see themselves as part of the society they had come to. In the other, they were not allowed to take on this view. These differences also shaped the way the rest of the society viewed these newcomers and additions to the population. In this context it is interesting to note that many Turkish migrants to Australia viewed themselves as coming temporarily, with the aim of returning to Turkey having saved a sum of money to establish themselves back 'home'. They report becoming 'permanent' as the accidental outcome of marrying and having a family while in Australia and coming to rather like the place (Bouma 1994).

Similarly, the Turkish communities in Germany found that the plan to return to Turkey after working in Germany temporarily for several years was not going to transpire. As cited by Talip Kucukcan (2009), according to a survey conducted in 1980, 40 percent of Turks living in Germany wanted to settle in Germany. In a later survey conducted in 1992 the number of those who wished to settle in Germany rose to 83 percent. Kucukcan (2009) refers to the establishment of over 50,000 Turkish small to medium enterprises as another indicator of permanent settlement in Germany. Nevertheless, the lack of permanence, particularly with the first generation, is also reflected in the fact that most Turks send the bodies of their deceased loved ones back to Turkey for burial. The distance and logistical difficulties in doing the same from Australia coupled with successful settlement may explain why Turkish communities generally choose to be buried in Australia.

The differences of Turkish migration to Australia to that of Europe are noted by the Australian Department of Foreign Affairs and Trade:

In 1967, Turkey and Australia signed a bilateral agreement on assisted migration. In contrast to the Turkish guest-worker schemes in Europe, Australia offered migration to whole families, as permanent migrants. The program resulted in an increase of the Turkey-born population in Australia from 1,544 at the 1961 Census to 11,589 in 1971. The 2006 Census showed that 59,393 Australian residents claimed Turkish descent, with 30,495 of those having been born in Turkey.

This reflection from Australia's Department of Foreign Affairs and Trade highlights a second major policy difference between Australia and European countries. Australia welcomed and promoted the migration of 
families and 'family re-unification' which allowed migrants to sponsor members of their extended family to come and join them. This had the effect of promoting the development of families and communities in the new country. Germany on the other hand focused primarily on the worker and was not particularly mindful of the needs of families for suitable education, health, or economic support.

There is a substantial demographic difference between Germany and Australia. The disparity in the number of Turkish Muslims in Germany and Australia are considerable. A total of 7,116 Turks had migrated to Germany as guest workers by 1961 . The figure reached to 910,500 by 1971 (Kilicli 2003). Recent figures indicate that there are 2.5 million Turks living in Germany, making it the largest Turkish community in Western Europe and the largest Turkish community outside of Turkey. Turks form 2.4 percent of Germany's population of 82 million (Kilicli 2003). They also comprise the vast majority of Muslims in Germany. The identity choices are limited by the failure of official policy to recognize Turks as German even if they have been born in Germany. The religious base of identity is problematic since Islam is not recognized as a religion and is not accommodated in social policy.

By way of contrast, in Australia, Turks make up about 0.3 percent of Australia's 20 million population. Again, by way of contrast with Germany, while 1.8 percent of Australia's population are Muslims, Turks only comprise about $13 \%$ of the Muslims in Australia. This makes Turks a minority among Muslims, although one of the larger sub-groups of Muslims, with only Lebanese at $13 \%$ of Muslims being a larger subgroup. The fact that over $25 \%$ of Australians were born overseas and 44 percent of Australians were either born overseas or have at least one parent who was born overseas clearly indicates that Australia is a settler society characterized by a high on-going rate of migration (Australian Bureau of Statistics, ABS 2009). In this case the demographics of Australia make identity formation a choice among various combinations: Australian-Muslim-Turkish, Australian-Turkish, Australian, Turkish, and Muslim. National, birth-place and religious identities compete for salience in identity formation. Australian social policy recognizes Islam, place of birth and other identity bases as not only legitimate, but as needing to be taken into account in social service delivery. 


\section{Policies of Inclusion and Exclusion}

A consideration of the larger socio-political context in which identity is constructed provides additional insight into the differences between Turks in Germany and those in Australia. For example, the Turkish communities in Germany suffer from being stigmatized because they are Turkish and because they are Muslim. While there are secular, Jewish and Christian Turkish people, the vast majority, 99.8\% of Turks in Turkey are Muslim (CIA World Factbook 2009), and this is also reflected in the Diaspora. The anti-Muslim fervor sweeping Europe, be it in France, Denmark, the Netherlands and more recently Sweden, situates the Turkish Muslims in Germany in an even more challenging context in terms of integration, identity construction, politicizations and conflation of cultural diversity with loyalty to the nation state. The socio-political environment, whether it is one of inclusion or exclusion, plays a part in the formation of identity as indicated in the expressed identities of Turkish communities in Australia and Germany.

From the 1960s Australian multicultural policy has generally provided an accommodating environment where diversity is increasingly acknowledged, welcomed and even celebrated. Such an inclusive atmosphere is typically present when the Labour Party is in government. However, during the ten years, 1996 - 2006 when the Liberal Party with John Howard as Prime Minister was in government, there was a shift away from an inclusive multicultural policy towards an exclusionary monoculture strategy. The introduction of a 'Citizenship Test' is an example of Howard's efforts to move away from a multicultural model to an assimilationist 'one nation' approach as is his refusal in employing the term multiculturalism (Tate 2009). Australia's multicultural policy was reaffirmed with the election of the Labour Party in 2007. The Prime Minister Kevin Rudd, in his visit to India amid the racist violence against Indian International students in Australia in mid-2009 reaffirmed internationally Australia's multicultural policy and provided assurance to the Indian Prime Minister Manmohan Singh in his statement:

"Australia is a country of great diversity, harmony and tolerance. We are a multicultural nation and we respect and embrace diversity, diversity which has enriched our nation"

Although the German Immigration Act of 2005 is an acknowledgment of Germany's recognition of itself as a 'society of migration', it does not present Germany as a multicultural society in 
terms of composition, policy or attitude. The approach in Germany is one of 'integration'. According to the Federal Office for Migration and Refugees (2009)

"integration policy should foster good relations between new and old members of society and enable people to cooperate with one another with respect and have equal rights of participation in society"

While integration is a positive step forward and is desired by both the Government and the Turkish communities in Germany, the interviews revealed that there is a significant degree of skepticism among the Turkish communities who view this as an assimilationist policy rather than one of integration. It is perceived as a political exercise rather a genuine effort to facilitate integration. Being stigmatized in the media and labeled as 'problematic' by government officials ostracizes the Turkish community. An interview with members of an international Turkish Islamic entrepreneurial organization in Berlin revealed a sense of mistrust towards the government's integration policies. Moreover, there was much concern raised over the lack of a comprehensive approach in the study on integration conducted by the Berlin Institute for Population and Development where Turkish migrants came last on the integration ranking (Elger and Theile 2009).

Despite the scope of the organization, they were not consulted in the study conducted by the Berlin Institute. The organization which is responsible for developing trade and business relations with Turkish and Muslim businesses in Germany internationally by employing their Turkish and Muslim affiliations taps into various markets and facilitates German business and exports. The members explained that their contributions to Germany, and the steps they take toward integration are unacknowledged, and explained that their invitations for official German representation to attend significant trade events were often declined. As such, the recognition of the positive steps taken towards integration, even on a symbolic level was futile. This has led the organization to draw the conclusion that calls for integration are not genuine. This attitude was expressed by a board member who explained: "They want assimilation rather than integration; assimilation under the guise of integration".

These examples of demographic, social policy and socio-political context differences shape the identity formation and degree of commitment to nation and place of Turkish migrants to Germany and Australia. In short, ironically Turks, although an enemy in World War I 
have been made to feel welcome in Australia; whereas in Germany, where they were allies in World War I they have not.

\section{Labeling and Identity construction}

Although labeling theory is frequently employed in the field of deviance and criminology, with particular reference to delinquency, it is appropriate to consider the impact of labeling on identity construction within the context of minority and immigrant groups as it is framed within the context of the imposition of a label by the powerful in society on the less powerful. While a label may not determine one's identity, as there are a number of variables that affect one's identity, the potential influences of labeling on identity formation are considerable. Selfconception can be shaped by societal labeling (Akers 1999).

The significance of government policy is particularly highlighted when it comes to the framing of issues and labeling people inside or outside of its borders. Government policy and official statements have the potential to influence self-conception, the identity and action of its minority residents, but also have the potential to influence the perceptions of the general public towards the minority group. Although such influences may not determine the self-conception or the perception of others, the potential it creates must be investigated. The Cronulla riot is a case-in-point and will be discussed in the following section.

Labeling alone will not determine one's self-conception. Individuals can react differently to labels: they may show defiance or try they may try to disprove them. For instance, non-commercial hip hop and rap in particular, are examples of resistance to oppression, racism, politics and labeling. As explained by Andy Bennet (1999: 77), hip hop and rap are platforms to disprove labels or show defiance, "a medium for the expression of issues relating to racism and the problem of national identity". Nevertheless, the need for having to disprove or show defiance also illustrates the impact of labeling. Moreover, the unfortunate consequences of sustained intense labeling combined with political rhetoric, media sensationalism and underlying xenophobic sentiments can fuel violence to acute levels as experienced in Australia in an incident commonly referred to as the 'Cronulla riot'. 


\section{Labeling: The Australian experience}

The Cronulla riot is provided as an example to illustrate (among other variables such as socio-economic circumstances) the impact and the influence of top-down policies and its impact on fuelling racism against the 'other'. Although, the people who were targeted were of Middle Eastern background or Muslim, coupled with the fact that the majority of Turks are Muslims, this case is nonetheless important in taking into account the potential impact of labeling. The Cronulla riot in 2005 on the shores of Sydney, Australia, illustrates the impact of government policy, official statements and media hysteria. The mass racist violence against the Muslim or Middle Eastern 'other' that erupted is explained by Professor Scott Poynting (2006: 85) as the:

'the culmination of a campaign of populist incitements waged in the media and by the state. The battles to reclaim control of the beach for white Australia mirrored... the battle that the Howard government has waged to reclaim control of the nation itself from asylum seekers and the Muslim/Middle Eastern 'enemy'.

Of particular significance is that the day after the riot, two-third of the callers to talk-back radio $2 \mathrm{~GB}$, expressed their support for what had taken place (Poynting 2006). Poynting explained this was a result of the 'permission to hate', which was conferred by the State.

Racism which lies beneath the surface usually rises in moments where a space is created, and permission is granted for expressions of sentiments of hate, usually through negative labelling by politicians and media hysteria. The fact that the then Prime Minister John Howard refused to recognize the mass violence as racist had the potential to influence how the violence was perceived by the general public, and his refusal to label it as such was a cause for concern among the community groups who were the target of the racist attacks. While violence on such a scale is not a common occurrence in Australia, the fact that 5000 people were mobilized in such a short amount of time is indicative of underlying xenophobic sentiments. And it is during these types of events, according to Rachel Woodlock (2009), that we see 'Muslim identity and Australian identity positioned as being in conflict with each other' and hear calls for 'Muslims to prioritize and demonstrate their loyalty to Australia and Australian identity'. While making detailed comparisons of incidences of racist violence in Germany is not within the scope of this paper, references will be made to racist violence in Germany. Notwithstanding 
these incidents of violence in Australia, there is also a sense of acceptance and celebration of cultural diversity as encapsulated in Australia. It is not uncommon to find in the streets of Melbourne, celebratory events being held with a variety of flags, food, music and culture of the diverse communities that make Australia what it is today. These community organisations receive assistance from various government departments such as the Victorian Multicultural Commission (VMC), Multicultural Arts Victoria, VicHealth as well as from private community businesses that sponsor the celebrations. The Victorian Multicultural Commission has a number of projects and initiatives such 'cultural diversity week', 'supporting refugees' and 'improving language services' (VMC 2009). Of particular significance, however, is 'Victoria's multicultural policy, "All of Us" which was launch in March 2009 after extensive state-wide community consultation. The policy sets out a framework for continuing to strengthen and promote multiculturalism across the state' (VMC 2009). Both community groups and members of the general public get together on these occasions and enjoy each other's company and cultures. As a result, feelings of respect and understanding are generated, and communities feel a sense of belonging.

Further contributing to the sense of belonging, acceptance, and an inclusive environment for identity development are Private Turkish and Islamic schools, which like Catholic and Jewish schools receive government funding and support. Grants are made available to community groups that assist their communities with issues related to health and wellbeing and women's groups among others. Although there are criticisms concerning insufficient funding, social inclusion and harmony is generally achieved. And it is within this environment that identity is constructed, retained or developed.

The time required for settlement, participation and identity formation is politicized, underestimated at best. According to Irving (1997) migrants' bonds to their country of settlement develop after a period of time, noting that when British settlers arrived in Australia, they were proud of British heritage. It is only after having lived in Australia for longer periods of time that they began constructing a new Australian identity (Irving 1997 cited in Kabir 2008). An excerpt of a speech given by the Premier of New South Wales, Henry Parkes in 1890 at the first Federation Conference sheds light on identity construction and the settlement process: "Make yourself a united people; appear before the world as one and then dream of going "home" would die away. We should create an Australian home..." (cited in Kabir 2008: 410). Kabir 
points out the fact that Parkes delivered this speech one hundred years after European-Australian settlement indicates the time it takes for the formation of national identity.

Issues of identity construction within the Turkish community in Australia are generally not a topic of concern. Issues of identity and integration are not framed in the context of the guest worker, or migrant, but rather within the context of Muslim identity and the perceived conflict between Australian and Muslim values. Accordingly when issues of identity become the flavor of the month among politicians or in the media, it by default affects the Turkish communities who are Muslim, more so those who are visibly Muslims. In terms if identity, being Turkish-Australian, or Australian with Turkish ancestry is generally not perceived as problematic by the wider society or by the Turkish communities. This is particularly noticeable in the fact that identity was not raised as an issue in the interviews that were conducted in Australia, in contrast to those held in Germany.

However, the fact that identity was not raised as an issue to the extent it was in Germany does not imply that there are no community members who identity themselves as 'only Turkish' in Australia. An interview conducted in December 2009 with professionals who work with Turkish communities in Victoria revealed that, particularly with regard to youth, that when they are not accepted by the wider society, or experience discrimination or racism, they identity with their Turkish heritage rather than Australian nationality. Subsequently, their interactions predominantly remain within the Turkish communities where they feel 'accepted' rather than engaging with the wider society where they are excluded despite having been born and brought up in Australia. In contrast, the experience of feeling Australian was also noted by another interview participant who runs a Turkish Islamic education centre, he explained, 'we are welcome here, and this is why we can say we are Australian'. While the incidents of discrimination must be addressed, the overall achievement of social cohesion is also highlighted in the 2009 national survey 'Mapping social cohesion' commissioned by the Scanlon and conducted by Andrew Markus (2009: 3) where it is reported that 'the overwhelming majority of Australians 95\% express a strong sense of belonging'. Concomitantly, 'about two out of ten Australia-born report having experienced discrimination over the course of their lives' (Markus 2009: 21). Albeit with issues of discrimination which require ongoing attention, diversity of cultures in Australian society is by and large managed within the multicultural framework. 


\section{Labelling: The German Experience}

Identity construction among Turkish Muslims in Germany differs significantly from that of Australia. The fact that there is no dualcitizenship in Germany potentially impacts one's identity and selfconception. Regardless of having immigrated and settled in Germany for decades, one cannot be German unless they relinquish the passport of their country of origin. The perceived injustices, such as discrimination in employment, experienced by Turkish Muslims in Germany enhance their affinity with Turkish identity. The vast majority of the Turks in Germany identified their national identity as being Turkish.

In addition to not having German citizenship, the geographical proximity between Germany and Turkey may also be a contributory factor in connecting with Turkish identity. The likelihood of travelling to Turkey regularly is more realistic than travelling from Australia. (Regardless of whether the travel is actualised or not - the possibility of travelling from Germany to Turkey is greater than travelling from Australia). It is more costly and takes approximately 20 hours by plane from Melbourne. This may explain the reason why there are a greater number of famous Turkish musicians performing in Germany as compared to Australia. These performances may reinforce the "Turkishness' of the identity of Turkish Muslims living in Germany.

While there is a stronger Turkish 'national' / 'ethnic' identity in Germany, there is also a trend in 'regional' or 'local' identity which excludes the 'nation' or ebbs its importance as the core identifier. In an interview that was conducted in Essen, Germany, the participant explained that when his children are asked, "Where are you from?", they say, "I am from Bochum" rather than saying "I am German or Turkish" or they say, "I am Turkish-German".

A shift away from a migrant focus to a broader multicultural approach may be useful to consider in Germany, particularly in education. Another experience that was relayed by the interview participant from the Essen region sheds light on the general perceptions held towards Turkish Muslims. His children were given migrant-specific worksheets at school, which they did not want to complete as they were unable to relate to them. Further, it is important to note that his children have German passports. The participant's sense of belonging is also important to consider, as he explained his sentiment: "Germany is my home and Turkey is where I was born and where I go to for holidays". 
The negative attitudes towards Turks and Muslims in general, according to interview participants are a result of the media's coverage of negative stories and disregarding positive success stories. Several participants referred to the "The Koln issue" where the building of a mosque became a point of controversy, noting that it was framed in a contentious manner and sensationalized in the media. Notably, the protesters from the extreme right-wing anti-immigration group, ProCologne who opposed the building of the mosque were confronted by demonstrators against the extremist group. In this situation, the proactive action taken by both the Cologne Mayor Fritz Schramma is noteworthy. The BBC report (2008) on the controversy cites Mayor Schramma who labeled pro-Cologne "arsonists and racists" hiding under the guise of a "citizens movement". Although the building of mosques usually generate controversy and concerns about integration, the establishment of mosques, according to Bouma (1994: 63) is 'evidence of the degree to which this group [Muslim] has settled in Australia' - noting that it provides a 'context for self-identification in the new homeland'. ${ }^{\text {i }}$ Despite the controversies, the mosque as a signifier of settlement and integration can also be seen in Germany. The Marxloh Mosque in Duisburg exemplifies successful settlement of Turkish Muslims in the region and the positive constructive relationship with the City of Duisburg. This is a mature and inclusive context in which identity is constructed and developed.

However, an interview participant in Hanover explained that, although Muslims constitute the second largest religious community after Christianity, they are not recognized by the government as a religious 'entity'. This means that Muslim community organizations are excluded from accessing significant state support and funds that are provided to Christian and Jewish community organizations. This is interpreted as a policy of exclusion which subsequently contributes to a sense of seclusion.

This lack of recognition is a barrier to access and integration, coupled with the repeated stigmatisation of the Turkish communities in Germany has a detrimental affect on the socio-political environment in which identity is constructed. The damaging comments made by Berlin's former finance minister, Dr Thilo Sarrazin are yet another example of negative labelling of minority groups by the influential in society. Appointed by the Germany's President Horst Koehler, Sarrazin is currently on the Board of Germany's central bank, the Bundesbank. Sarrazin's derogatory statements about the Turkish and Arabic 
population in Berlin, were published in a German cultural magazine, Lettre International, where he expressed his views that the Berlin's Turkish and Arabic communities have low IQs and "no productive function other than the fruit and vegetable trade" (Crossland 2009). Although the governor of Bundesbank, Alex Weber has made an effort to distance the bank from Saraazin's xenophobic remarks and expressed concern about the damage he has caused to the bank's reputation, President Koehler who has the authority to discharge Sarrazin from his position, has refused to exercise this power. Nevertheless, Sarrazin is reportedly under police investigation for his comments which may be in breach of Germany's anti-racism laws (Evans-Pritchard 2009).

The concern over the implications of Sarrazin's comments are highlighted by the chairman of the Turkish Community in Germany, Kenan Kolat who is reported in the United Arab Emirates paper, The National as saying: "Such remarks are grist for the mill for right-wing extremists. Mr Sarrazin doesn't think about what impact his words have".

The impact of Sarrazin's words can be seen in light of the 'permission to hate' conferred by the state. The incident of vandalism in the Bavarian town of Elsenfeld where balloons filled with animal blood were hurled at the mosque and 30 animal eyes placed at its entrance occurred soon after Sarrazin's prejudiced statements. According to the Spokesman of German Islamic Council, Engin Karahan, the attacks against the mosque are connected to the controversial debates which include the divisive remarks made by Sarazzin. Karahan is reported in the German paper, The Local (2009) as saying, in the context of constant disparagement that it is not surprising, that "crazy people feel compelled to carry out such acts", and explained that the attack emerged within "a certain atmosphere" that is prevalent in society at the moment. The certain atmosphere can be seen in light of the space that is created where 'permission to hate' is conferred by the state.

On the $3^{\text {rd }}$ of February 2008, nine Turkish people living in Germany, five children and four adults, died in a fire that engulfed their home. There was speculation over the nature of attack and concern that it was racially motivated. However, German authorities do not deem it to be a racially motivated attack. As reported by M Sezer in the Associated Press (2008), the 'neo-nazi graffiti near the door of Turkish cultural centre in the same building was unrelated to the fire, German authorities said.' Nevertheless this did not allay the concern of relatives who suspected that antagonism toward minorities may have played a part in the fire. Karanfil Calar, the mother of Hulya Kaplan who died in the fire 
is reported as saying, "There has been hostility towards Turks, the German government did not take it seriously". Silence, the lack of action as much as active negative labeling, contributes to the space that is created where not only identity is developed, and self-conceptualization take place, but also where permission is conferred by the state to express sentiments whether it is in the form of racist graffiti, in balloons filled with animal blood or potentially in the form of extreme violence that can lead to physical harm, even death.

\section{Conclusion}

In this paper, we proposed that the labeling of minority groups has an impact of identity construction, on the self-conception of the individuals, as well as the perception of the wider-society of the minority group. We have argued that labeling creates a space for the expression xenophobic sentiments giving 'permission to hate', which is conferred by the state or by people in positions of influence. The socio-political environment in which identity is formed in Europe, and in particular Germany, is different to that of Australia. While the rhetoric concerning identity and integration is played out in Australia every now and again, the dominant frame within which it is debated is nevertheless to an extent, even if on a symbolic level, inclusive and multicultural. This however does not mean the state is only responsible for identity construction, integration and for unfortunate incidents of violence and vandalism. The Turkish community itself needs to work within the matrix of the German context which is not as conducive as the Australian context.

Note: The research for this paper was supported in part by a grant from the Group of Eight Universities and DAAD, as well as by an Australian Research Council Linkage Grant to study 'What Muslims Want'. 


\section{References}

Appadurai, Arjun.

1996 Modernity at Large: Cultural Dimensions of Globalization.

Minneapolis: University of Minnesota Press.

Akers, L. Ronald.

1999 Criminological Theories: Introduction and Evaluation ( ${ }^{\text {nd }}$ Ed.). (London: Fitzroy Dearborn, 1999). (p. 99).

Bouma, Gary.

1994 Mosques and Muslim Settlement in Australia. Australia: Bureau of Immigration and Population Research.

Kucukcan, Talip.

2009 Turks in Germany: At the Margins or at the Periphery? Turkish

Daily News (27 March0 Retrieved 20 November, 2009, from

http://www.setav.org/index.php?option=com_content\&task=view $\underline{\text { id }=111 \& \text { Itemid }=29}$

Department of Immigration and Citizenship. Community Information Summary: Turkey-born.

Retrieved April 2, 2009 from

http://www.immi.gov.au/media/publications/statistics/commsumm/_pdf/turkey.pdf

Kilicli, Ayca.

2003 Turkish Migrants in Germany, Prospects of Integration. EUTurkish Relations Dossier. Observatory of European Foreign Policy. Retrieved November, 20, 2009, from http://www.iuee.eu/pdfdossier/12/rXNHUsicpVwS6Cd7AQHA.PDF

Australian Bureau of Statistics

2009 Perspectives on migrants. Retrieved 20 November, 2009, from

http://www.abs.gov.au/AUSSTATS/abs@.nsf/Lookup/3416.0Mai $\underline{\mathrm{n}+\text { Features} 22009}$

CIA. The World Factbook - Turkey. 
(2009, November 27). Retrieved November 27 2009, from https://www.cia.gov/library/publications/the-worldfactbook/geos/tu.html

Tate, John.

2009 Howard's "Nation" and Citizenship Test: Multiculturalism, Citizenship, and Identity. Australian Journal of Politics and History. 55(1), (March, 2009) 97-120

Federal Office for Migration and Refugees. Social integration.

Retrieved January 12, 2009 from www.integration-indeutschland.de/nn_433388/Subsites/Integration

Elger, Katrin; Kneip, Ansbert and Theile, Merlind.

2009 Survey Shows Alarming Lack of Integration in Germany. Spiegel (2009). Retrieved January 26, 2009 from

http://www.spiegel.de/international/germany/0,1518,603588,00.ht $\underline{\mathrm{ml}}$

Bennett, Andy.

1999 Hip hop am Main: The Localization of Rap Music and Hip Hop Culture. Media, Culture \& Society, 21(1), 77-79.

Poynting, Scott.

2006 What caused the Cronulla Riot? Race \& Class, 48(1), 85-92 (p. $85)$.

Woodlock, Rachel.

2009 Being an Aussie Mossie: Muslim and Australian identity among Australian-born Muslims. Islamophobia: Fear of the Other Conference, 18-19 July 2009. Victoria, Australia: Monash University, Australian Catholic University, and the Australian Intercultural Society. (To be published)

Victorian Multicultural Commission. Multicultural Victoria . http://www.multicultural.vic.gov.au/projects-and-initiatives

Kabir, Nahid.

2008 "To be or not to be Australian: Focus on Muslim Youth".

National identities, 10(4), 399 - 419 (p.409-410)

Irving, Helen.

1997 To Constitute a Nation: A Cultural History of Australia's Constitution. (Cambridge: Cambridge University Press 
Markus, Andrew.

2009 Mapping social cohesion: The Scanlon foundation surveys summary report. Australia: the Scanlon Foundation (p. 3).

BBC News.

2008 Street clashes erupt in Germany (20 September). Retrieved November 20, 2009 from

http://news.bbc.co.uk/2/hi/europe/7627047.stm BBC news.

Crossland, David.

2009 German Official insults Arabs and Turks. The National (6 October). Retrieved November 20, 2009, from http://www.thenational.ae/apps/pbcs.dll/article?AID=/20091007/ FOREIGN/710069877/1013

Evans-Pritchard, Ambrose.

2009 "Bundesbank Official under Police Investigation after blasting Turks for 'conquering Germany"'. The Telegraph. (October 4, 2009). Retrieved November 20, 2009, from

http://www.telegraph.co.uk/finance/newsbysector/banksandfinanc e/6259427/Bundesbank-official-under-police-investigation-afterblasting-Turks-for-conquering-Germany.html

The Local.

2009 "Animal blood thrown at Bavarian mosque", (25 October)

Retrieved November 20, 2009, from

http://www.thelocal.de/national/20091025-22801.html

Sezer, Murad.

2008 "Turks bury German fire victims", Associated Press. (11

February) www.newsvine.com/_news/2008/02/10/1292756-turksbury-germany-fire--victims 